\title{
Sentenças existenciais à luz da semântica de frames
}

\section{Existential sentences in the light of semantics frame}

\author{
Lucas Alves Costa ${ }^{1}$
}

\begin{abstract}
Resumo: Este trabalho analisa o sentido existencial, acomodado em sentenças existenciais com verbos Haver, Ter e Existir recorrentes no português brasileiro. Para tanto, a análise pauta-se na Semântica de Frames, nos termos de Fillmore (1982, 1985), Fillmore e Atkins (1992), Salomão (2009) e Ferrari (2014), pois consideram o sentido o resultado de um conjunto de conhecimentos de mundo calcados na experiência sensória-motora do ser humano no meio ambiente. Utilizam-se dados da língua portuguesa contemporânea depreendidos de textos que circulam na grande mídia brasileira. Constata-se que a sentença existencial é um perfilhamento de um frame base, uma cena conceptual-perceptiva, independente do verbo instanciado.
\end{abstract}

Palavras-chave: Semântica de frames; Léxico e sintaxe; Sentença existencial.

Abstract: This paper analyzes the existential sense, accommodated in sentences existences with verbs Haver, Ter and Existir existing in Brazilian Portuguese. In order to do this, the analysis is based on Frame Semantics, according to Fillmore (1982, 1985), Fillmore and Atkins (1992), Salomão (2009) and Ferrari (2014), since they consider meaning the result of a set of knowledge of the world on the sensory-motor experience of the human being in the environment. Data from the contemporary portuguese language are taken from texts circulating in the mainstream Brazilian media. It is verified that the existential sentence is a derivation of a base frame, a conceptual-perceptive scene, independent of the instanced verb.

Keywords: Semantics of Frames; Lexicon and syntax; Existential Sentence.

\section{Palavras Iniciais}

Pesquisas quantitativas de cunho sociolinguístico como Oliveira (2014) e Avelar (2006a) constataram a recorrência de sentenças existenciais com os verbos Ter, Haver e Existir no português brasileiro. As possibilidades sintagmáticas e as variações de sentido desses verbos são grandes, porém não é objetivo, deste trabalho, discutir as várias acepções convencionais provocadas por eles, pois esse

\footnotetext{
1 Doutorando em Estudo Linguísticos no Programa de Pós-Graduação Letras e Linguística - FL/UFG. O presente trabalho foi realizado com apoio da Coordenação de Aperfeiçoamento de Pessoal de Nível Superior - CAPES. E-mail: lucas.alves.77@gmail.com.
} 
texto se restringe a investigar o sentido de existência, compartilhado por esses itens lexicais em sentenças existenciais.

A Gramática Normativa e as pesquisas Sociolinguísticas discutem a competição entre os verbos Haver e Ter. Dessa forma, em sentenças existenciais, o verbo Ter vem sendo utilizado no sentido de existência ao invés do uso do verbo Haver, considerado mais canônico nessas sentenças. Gramáticos Normativos como Almeida (1999), Cunha e Cintra (2001), Bechara (2006) e Sacconi (2001) consideram a variação entre esses verbos uma incorreção no padrão culto da língua, pois o verbo Haver, nessa perspectiva, apresenta a acepção de Existir, sendo esse o padrão correto da língua.

Cunha e Cintra (2001) afirmam que não só na linguagem coloquial do Brasil, como também no Português de nações africanas é corrente o emprego do verbo Ter como impessoal à semelhança de Haver. Porém, é preciso manter a "correção" e preferir o uso de Haver como existencial. Bechara (2006) admite que a frequência de uso de Ter por Haver seja amplamente maior em situações informais, o autor explica que esse emprego constitui uma incorreção na língua culta, devendo ser evitado.

Diferentemente das abordagens normativas, as pesquisas sociolinguísticas mostram que as sentenças existenciais são elaboradas com o verbo Ter na língua falada e na língua escrita. Assim, o processo de substituição de Haver por Ter apresenta-se num estágio avançado, dependendo da escolarização e da origem social do usuário da língua.

Leite e Callou (2002), com foco em cinco capitais brasileiras, mostram o alto percentual de uso de Ter sobre Haver em estruturas existenciais. Segundo as autoras, Ter chega a 73\% em Porto Alegre e Salvador, $68 \%$ em Recife, $63 \%$ no Rio de Janeiro e a 56\% em São Paulo. Para as autoras, esses percentuais de uso de Haver vêm sofrendo uma redução significativa.

Os embates entre a proposta da Gramática Normativa e as constatações da Sociolinguística para o uso concorrente entre o verbo Ter e Haver são filiadas a visão composicional do sentido. Com isso, o sentido de existência, para essas perspectivas, é acoplado no sentido lexical dos verbos utilizados nas sentenças.

Dessa forma, o procedimento de descrição semântica, nesta perspectiva, realiza-se por traços distintivos, baseados em uma oposição binária (presença ou ausência de um traço). Segundo Tamba (2012), essa abordagem é calcada no modelo fonológico de L. Hjelmslev e foi praticada pelo estruturalismo americano sob orientação de Bloomfield. Assim, léxico é tido com um elemento independente da sintaxe, e essa, por sua vez, de certa forma, autônoma.

A Gramática Gerativa também sustenta essa visão composicional do sentido. Segundo Tamba (2012), essa teoria transporta a semântica do léxico para a semântica da frase. Com isso, há o abandono de uma semântica lexical focalizada nas relações entre as palavras e as ideias em proveito de uma semântica frástica, centrada nas relações entre as estruturas sintáticas e semânticas. Chomsky (1957) defende a autonomia da sintaxe, mas estabelece uma relação mais próxima entre léxico e sintaxe. Com isso, o componente sintático permanece no núcleo do dispositivo gerativo da gramática.

De maneira geral, essas teorias são calcadas no princípio básico da constituição de gramática a partir da visão composicional (GUREVICH, 2006). De acordo com essa postura, o significado de um todo linguístico (de uma sentença ou de uma palavra) pode ser completamente concebido a partir dos significados das partes que o compõem (as palavras, no caso das sentenças, e os morfemas, no caso das palavras). 
Neste trabalho, assume-se o princípio da não separação rígida entre léxico e sintaxe (FERRARI, 2014; FILLMORE, 1982). Essa visão rompe com a ótica composicional praticada pelo Estruturalismo. Na ótica composicional, em se tratando de léxico, a análise sêmica propõe a decomposição do sentido das unidades lexicais em um número finito de componentes semânticos elementares.

Para Ferrari (2014), a Linguística Cognitiva, em seus vários paradigmas, rompe com essa perspectiva, pois assume que o todo determina a parte, ou seja, o significado base que determina quais partes (palavras ou morfemas) devem ser usadas na situação de interação comunicativa. Nessa perspectiva, verifica-se a constituição do sentido de existência em ocorrências com o verbo Haver, Ter, Existir depreendidas de uma amostragem de língua escrita que circulam em textos na mídia brasileira.

Para esse propósito, acionam-se os procedimentos da Semântica de Frames, de Fillmore (1968, 1982, 1985) e Fillmore e Atkins (1992). Nesse modelo, o significado é resultado de um conjunto complexo de conhecimentos de mundo armazenados na memória individual e coletiva, sendo as experiências sensoriais-motoras do ser humano no meio ambiente sua fonte primordial.

Este trabalho organiza-se da seguinte forma: na segunda seção, acionam-se as noções básicas e procedimentais da Semântica de Frames para análise do sentido de existência proveniente em sentenças existenciais. Na terceira seção, realiza-se a análise de amostra de dados de língua escrita depreendidos para este trabalho. $E$, por fim, na quarta seção, as palavras finais.

\section{Semântica de Frames}

Para Fillmore (1985), a Semântica de Frames faz parte de uma Semântica da Compreensão em oposição à Semântica da Verdade. Segundo Lyons (1977), a Semântica da Verdade apresenta duas concepções básicas sobre a composição do sentido: (1) evoca teorias que se preocupam em determinar elementos necessários para a interpretação de uma sentença, palavra, considerando as situações em que se estabelece, verificando a presença ou ausência de traços pré-definidos como componente básico para uma interpretação; (2) agrupa teorias que buscam determinar sob quais condições uma sentença pode ser verdadeira, sendo o verdadeiro determinado composicionalmente.

Fillmore (1985) apresenta o modelo da Semântica de Frames como uma Semântica do Entendimento, em oposição à Semântica Formal. Segundo Lyons (1977), a Semântica Formal é baseada no silogismo que testa as condições que viabilizam uma sentença como verdadeira ou falsa a partir de categorias lógico-formais e métodos analógicos dos processos de raciocínio.

Com isso, segundo Fillmore (1982), a Semântica de Frame é uma abordagem de fraca composicionalidade, porém mantém um lado composicional, visto que considera os processos de elaboração de sentido dependentes dos itens lexicais, unidades fraseológicas e construções gramaticais individualizados. Entretanto, define-se como não composicional, pois o processo de constituição do sentido não é puramente construído por concatenações de itens ou estruturas linguísticas, mas por vários conhecimentos associados a ele.

O ponto fundamental, nessa perspectiva, é a noção de que "os significados são relativizados às cenas" (FILLMORE, 1985, p. 59). Por conseguinte, a Semântica de Frames aproxima-se da tradição da Semântica Empírica e se afasta da tradição formal, pois considera a interação entre linguagem e 
experiências. Segundo Fillmore (1982), a semântica de um item lexical, tomado até mesmo isolado, interage com a cena ativada por ele, pois a constituição de significado de uma expressão requer um processo que ative a cena conceptual em que ela se insere.

Dessa forma, as palavras representam "categorias de experiências", que aparecem a partir de um contexto de conhecimento e de experiências específicas. Assim, a Semântica de Frames pode ser concebida como um esforço para entender as motivações de um grupo de usuário de língua para elaborar determinada categoria representada pela palavra e explicar o significado da palavra demonstrando e estabelecendo suas razões.

Fillmore (1982) considera que as palavras e qualquer outra forma e categorias linguísticas indexam categorias semântico-cognitivas, essas, por sua vez, são reconhecidas como participantes de alguma estrutura de conhecimento maior, ou seja, cultural. Para Ferrari (2014), isso permite explicar por que a interpretação de um enunciado envolve sempre mais informações do que aquelas diretamente codificadas na forma linguística. O primeiro ponto necessário nessa perspectiva é a noção de frame, pois é nessa noção que as categorias semânticas ou cognitivas são indexadas às palavras ou outras formas linguísticas.

Segundo Fillmore (1982, p. 111), um frame é como "qualquer sistema de conceitos relacionados de tal forma que para entender um deles é necessário entender toda a estrutura na qual ele se encaixa". Ferrari $(2014$, p. 50) destaca que o termo frame "designa um sistema estruturado de conhecimentos, armazenados na memória de longo prazo e organizado a partir da esquematização da experiência". Assim, o significado das palavras é subordinado ao frame.

Por conseguinte, o conceito de frame é então postulado nos termos seguintes:

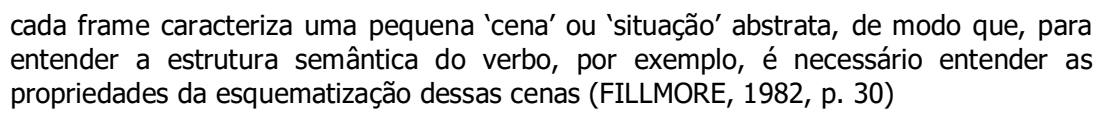

Com isso, essa noção de frame proporciona lidar com estruturas de conhecimentos implícitas (conhecimento do mundo) a partir das quais se operam processos semânticos de inferenciação. Segundo Fillmore (1985), a intepretação de um item lexical da língua depende, substancialmente, dos processos de inferenciação invocados por esse item lexical e por estruturas sintáticas instanciadas. Dessa forma, acessa-se o conhecimento de mundo para identificação do significado. Assim, sem recuperar o contexto conceptual (background) desse item não é possível estabelecer seu sentido.

Para exemplificar, utilizam-se os exemplos dados por Fillmore (1982) que apresentam os verbos Comprar, Vender, Pagar, Gastar, Custar e Cobrar. O autor afirma ser imprescindível acessar o frame de Evento Comercial para interpretá-los. Dessa forma, é esse frame que fornece a base motivadora dos processos representados nesses itens lexicais.

Por exemplo, "O professor comprou o livro", "João vendeu o carro", "O professor pagou R $\$ 30,00$ pelo livro", "O livro custa $R \$ 30,00 "$ e "A livraria cobra $R \$ 30,00 "$ ". Segundo Fillmore (1982), cada uma dessas sentenças exige o acesso ao frame Evento Comercial para serem interpretadas, mesmo cada uma delas destacando perspectivas particulares desse frame, isso é demonstrado pela seleção dos verbos. Esse contexto conceptual é fornecido pela estrutura dos frames, sendo os verbos selecionados instâncias desse frame. 
Segundo Gawron (2008), frames são estruturas conceptuais que fornecem contextos para a interpretação de elementos. Explica-se, a partir dessa noção, como nosso entendimento pode ir além do que o texto está dizendo literalmente. Por exemplo, ao reativarmos o frame "restaurante", mobilizamos um conjunto de ações, falas, rituais culturais, etc. associados a ele, podendo apresentar características variadas, mas o esquema não deixa de ser reconhecido: o restaurante, podendo ser regional ou internacional, podendo ter um funcionamento do tipo self-service ou de rodízio, pode ser dançante, pode ser típico, etc.

Visto a noção de frame, outro ponto essencial para entender a construção do significado nessa abordagem: a noção de perspectiva. Fillmore (1985) desenvolveu a noção de perspectiva em seu trabalho sobre a cena de transação comercial. Nessa cena, estão envolvidos dois indivíduos diferentes que atuam agentivamente: um dos indivíduos - o comprador - entrega o dinheiro para levar a mercadoria; o outro o vendedor - recebe o dinheiro e entrega a mercadoria.

Dessa forma, segundo Fillmore (1985), a descrição completa desta cena deve identificar o comprador, o vendedor, o dinheiro e a mercadoria. Para Fillmore (1985), a escolha verbal determina a perspectiva estabelecida sobre a cena. $\mathrm{O}$ verbo Vender, por exemplo, põe em perspectiva o vendedor e a mercadoria (João vendeu o carro), enquanto em Comprar a mercadoria é colocada em perspectiva com o comprador ( $\mathrm{O}$ professor comprou o livro). Já em Custar, a mercadoria é perspectivada com o dinheiro ( $\mathrm{O}$ livro custa $R \$ 30,00)$.

Para Fillmore (1985), cada um desses verbos designam uma perspectiva particular do evento. Assim, cada verbo escolhido pelo usuário da língua aponta para uma "rota" específica para interpretação de um determinado frame. Com isso, também o modo de relacionar os vários papéis semânticos para destacar certos aspectos do frame. Todavia, a cena básica do evento é mantida e serve de pano de fundo para compreender as "rotas" específicas escolhidas pelo usuário da língua.

Segundo Salomão (2009), frame envolve o conhecimento (cultural) de práticas sociais convencionais, isso torna possível conceptualizar e verbalizar (esse conhecimento) em sequências de ações planejadas detalhadas em frases. Assim, há a presença de diversos conhecimentos para as construções do significado, sendo esses conhecimentos estruturados em forma de frame, permitindo aos usuários de uma língua se entenderem e usarem as palavras cotidianamente.

Ferrari (2014) afirma que a noção de frame traz implicações ao entendimento de noções problemáticas como significado e conceito. Para a autora, a visão tradicional assume as palavras específicas como correspondentes a conceitos particulares, ou seja, essencialmente idênticos na mente do usuário da língua. Com isso, os conceitos são caracterizados em termos objetivos com base no estabelecimento de listas de traços semânticos. Todavia, essa noção desequilibra essa perspectiva, visto que descarta a visão de significado como entidade e, segundo a autora, trata-o como função.

Especificamente, em relação ao sentido de existência, Givón (2012) afirma que não percebemos as coisas em si mesmas, mas sim interpretamos a partir de um universo de input que é por si aleatórios. Assim, o universo tal como dado a nós e aparentemente ordenado deve ser o resultado da calibragem da nossa cognição-percepção.

Para Givón (2012), a existência configurada nas línguas humanas segue uma escala implicacional, ou seja, de aspectos mais genéricos, 'concreto', 'temporal' e 'abstrato' até a individualização. Para o autor, 
na escala há 'existir no espaço', 'existir no tempo' e 'existir' respectivamente. A progressão acontece nessa escala em contínuo, onde um ponto não é possível sem o outro. Com isso, temos:

Existir no tempo > Existir no espaço > Existir

Nessa escala, Givón (2012) delineia as construções sintáticas que tratam apenas de identificação ou existência, como nos exemplos a seguir:

(1) Há um homem que é importante aqui. (EXISTENCIAL)

(2) É esse homem que é importante aqui. (IDENTIFICAÇÃO)

Em (1), a entidade 'homem' passa a existir no plano do discurso sem nenhum compromisso do locutor em individualizá-la para o interlocutor, essa inserção de entidade estabelece a função de fazer existir no plano discursivo sem compromisso ontológico. Já o (2), a própria expressão 'esse' já demonstra uma retomada da entidade presente no conhecimento partilhado dos envolvidos na interlocução, assim o compromisso é identificá-la frente a tantas outras já existente.

Considerando essa distinção entre existência e identificação, Givón (2012) apresenta a primeira dimensão para interpretação do universo, a dimensão temporal. Essa dimensão, para o autor, é codificada nas línguas pelos nos verbos. Os verbos mapeiam entidades que são menos concretas do que os nomes (ações, eventos, estados, processos), as quais tipicamente têm apenas existência no tempo. Já a dimensão espacial, mais concreta, é codificada nas dêixis espaciais. Por fim, para o autor, os nomes, mais concretos, são caracterizados, logo individualizados, por serem indicadores de espaço aparentemente preenchidos.

Givón (2012) afirma que a ordenação das coisas no mundo é dada pelo tempo, e isso torna possível a individualização de entidades. Porém, essas entidades são pontos na escala temporal, sendo objetos da percepção, por si mesmos, não são unidades atômicas de fato. A calibragem perceptual do espaço que estabiliza a escala temporal, e é nessas ferramentas de intepretação - percepção-cognição que as coisas passam a existir.

As considerações de Givón (2012) remetem para o pressuposto fundamental da Semântica de Frames: os significados são constituídos com base em experiências sensórias-motoras no meio ambiente e compartilhados convencionalmente pelo grupo de usuário da língua, isso implica considerar que uma palavra ou uma sentença, na verdade, são pontos de acesso a um significado base, uma cena perceptivacognitiva, conceptual.

Fillmore (1982), todavia, afirma que o significado das palavras é caracterizado com base nas experiências, esquematizadas conforme o conhecimento do usuário da língua. Logo, essa esquematização em frames representa situações prototípicas da língua. Assim, um frame semântico, evocado por uma unidade lexical, conduz a uma representação de imagens e crenças, esses elementos podem variar de uma cultura para outra. Para Fillmore (1982), os elementos de frame apresentam-se como argumentos dentro de uma sentença e permitem acessar a relação entre as palavras ou elementos e um dado frame.

A Semântica de Frames lida com estruturas de conhecimento implícitas (conhecimento cultural do mundo) a partir das quais se operam processos semânticos de inferenciação. No caso das sentenças existenciais, a inferenciação recai sobre o sintagma nominal inserido no plano do discurso. Afinal, o Observador, na maioria das vezes, pressupõe que seu interlocutor compartilha do mesmo conhecimento 
no momento do ato de enunciação. O padrão sintático Verbo>Sintagma Nominal>operador LocativoTemporal é parcialmente estativo nessas sentenças, nota-se que não há uma elaboração sequencial para definir o objeto de discurso inserido, há a ação de fazer conhecer, compartilhar essa informação por meio da inserção do objeto de discurso.

Segundo Costa (2018), as sentenças existenciais acionam o frame da cena Estado de Existência. Ela inclui os seguintes elementos abstratizados: Observador, Campo Visual e Entidade Focalizada. O observador corresponde a um sujeito consciente, ou seja, alguém que já testemunhou direta ou indiretamente a cena ou evento; Campo Visual corresponde à totalidade do horizonte de consciência acessível ao Observador (incluindo o estado interno); Entidade Focalizada é inserida no plano discursivo, ou seja, existe na sequência de fala/escrita. Costa (2018) apresenta uma ilustração para representar esses elementos:

Figura 1 - Cena Estado de Existência
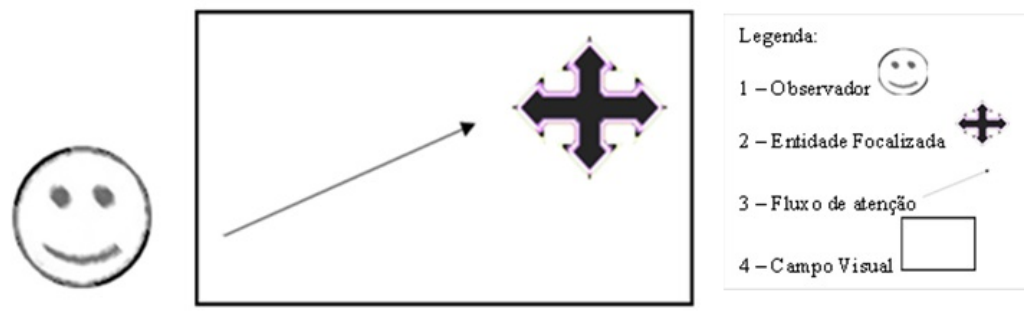

Fonte: Adaptado de Costa (2018, p. 69)

A Figura 1 traduz visualmente a cena Estado de Existência. Essa cena conceptual é um frame, nos termos de Fillmore (1982). Nesse frame, há a constatação da existência de algo no plano do discurso, não mantendo nenhum compromisso ontológico, se existe ou não na realidade. Dessa forma, não evidencia precisamente a fonte de conhecimento, tornando o observador a fonte principal da informação dada e codificada na sentença existencial.

Assim, aplicam-se essas noções na análise do sentido de existência em sentenças existenciais no português brasileiro. A alternância entre os verbos é licenciada pelo frame básico Estado de Existência, proveniente de conhecimentos experienciados na intersubjetividade. Na próxima seção, realiza-se a análise de uma amostra de dados escritos da língua, verificando as relações de sentido estabelecidas na sentença com o frame básico configurado pela gramática.

\section{Análise de sentenças existenciais}

Metodologicamente, o corpus deste trabalho foi constituído a partir de um conjunto de exemplários de frases depreendidas de textos escritos em jornais divulgados na internet. Verificou-se, nos últimos três meses, em páginas públicas de jornais brasileiros na rede social Facebook, frases com verbos Ter, Haver e Existir em notícias, propagandas, manchetes e comentários de seguidores dessas páginas. 
Para a identificação de sentenças existenciais utilizam-se os critérios de Pezzati (1993), ou seja, presenças de verbos Ter, Haver, Existir; preposição do verbo, impessoalidade, sintagma nominal posposto ao verbo não sendo argumento interno nem externo e presença de expressão locativa ou temporal.

Dessa forma, parte-se da constatação que os verbos Ter, Haver e Existir são os mais frequentes nas sentenças existenciais, sendo que esses verbos servem para introduzir um novo elemento no plano discursivo (TRASK, 1995; PEZZATI, 1993; AVELAR, 2006a; VITÓRIO, 2008). A Semântica de Frames, como afirma Fillmore (1985), não desconsidera os elementos lexicais, afinal partem-se deles para a compreensão dos frames acessados por esses itens. A seguir, exemplos de sentenças existenciais:

(3) Há vagas (propaganda)

(4) Tem um jeito novo de fazer mudanças! (propaganda)

(5) Aqui há o que você precisa...(propaganda)

(6) Há 7 anos não falo com Faustão. (Manchete, 2017)

(7) Entenda por que há tantas palavras do ano em 2016. (Manchete, 2017)

Nesses exemplos, o aspecto gramatical se configura nas seguintes formas: (i) os verbos em terceira pessoa do singular, encadeando a impessoalidade; (ii) o predicador não seleciona um argumento externo, ou seja, dispensa o Sujeito; (iii) há um Sintagma Nominal posposto ao verbo que na maioria dos casos, carece de especificidade; (iv) em muitos casos, um marcador locativo-temporal. Esses aspectos caracterizam uma sentença existencial (PEZZATI, 1993). Nos exemplos abaixo, verifica-se a alternância entre Ter e Haver:

(8) Há vários jeitos de chegar na cidade! (comentário)

(9) Tem vários jeitos de chegar na cidade! (comentário)

As ocorrências (8) e (9) ilustram a concorrência entre o verbo Haver e Ter que são objeto de embates entre a Gramática Normativa e pesquisas sociolinguísticas. Na verdade, isso demonstra que essas perspectivas ressaltam que o sentido de existência depende somente do léxico. Diferentemente, a Semântica de Frames defende o contínuo entre léxico e sintaxe, orientado pelo domínio conceptual, visto que é o frame que fornece a base motivadora dos processos que constitui o sentido nas palavras. A seguir exemplos depreendidas de textos escritos:

(10) Tem tanta gente nesse lugar hoje. (notícia)

(11) Há caminhos que me levam a você! (propaganda)

(12) Há um golpe em curso no Brasil. (manchete)

Esses exemplos são design prototípicos de uma sentença existencial e que acessam a cena de Estado de Existência para serem interpretadas, embora cada uma delas destaque aspectos particulares desse frame em função da seleção do verbo. Nota-se que os verbos instanciados têm a função de inserir um objeto de discurso na sequência enunciativa, porém a expressão locativa ou temporal contribui na 
configuração do sentido da sentença existencial. Isso demonstra que o sentido de existência acopla as noções de espaço e tempo.

(13) Tem funcionário sem salários no Rio, disse Pezão. (manchete)

Nota-se que (13) é uma fala reportada, ou seja, é resgatada a fala de outra pessoa que não seja o falante do enunciado, acionando a cena Estado de Existência. A expressão linguística "Pezão" (pelos conhecimentos compartilhados sabemos que é o governador do Estado do Rio de Janeiro) corresponde ao Observador, que também é a fonte da informação dada. Essa sentença existencial, instanciada com o verbo Haver, acessa aos elementos Entidade Focalizada pelo Observador, realizada pela expressão linguística "funcionários sem salários". O Campo visual, ou seja, a noção espaço-temporal é acessada pela expressão linguística "no Rio". Toda a interpretação que fazemos de (13) nos encaminha para o conhecimento dessa situaçã̃o, sendo o Observador a fonte dessas informações.

Considera-se que a configuração da cena Estado de Existência esteja, como demonstrou Givón (2012), no estágio mais concreto, estático em relação a percepção do observador. Por conseguinte, o tempo (presente do indicativo), codificado no verbo, calibra a percepção para uma aparente estabilidade. O aspecto temporal é configurado no 'agora' do evento. A impessoalidade nesse frame não é uma estratégia discursiva de neutralização, mas um deslocamento para o ente evidenciado no plano discursivo, codificado no Sintagma Nominal. Com isso, o predicador não exige um sujeito na oração. Assim, nessa cena conceptual, frame, a percepção-cognição está voltada para o ente a ser apresentado. Decorre, assim, a colocação em proeminência da existência de algo no plano do discurso.

Ressalta-se que Semântica de Frames lida com estruturas de conhecimento implícitas (conhecimento do mundo) a partir das quais se operam processos semânticos de inferenciação. No caso das sentenças existenciais, a inferenciação recai sobre a Entidade Focalizada introduzida no plano do discurso. Afinal, o Observador pressupõe que seu interlocutor compartilha do mesmo conhecimento no momento do ato de enunciação. O padrão sintático Verbo>Sintagma Nominal>operador LocativoTemporal é estativo nessas sentenças, percebe-se que não há uma elaboração sequencial para caracterizar o objeto inserido. Observam-se esses exemplos:

(14) Existe ${ }^{2}$ livros na biblioteca! (notícia)

(15) Há uma pressão da oposição no Senado.

(16) Tem uma cidadezinha aqui perto! (comentário)

Nota-se que (14), (15) e (16) apresentam o mesmo sentido de existência, independente do verbo instanciado. A introdução da Entidade Focalizada no plano do discurso (que está em negrito) se dá na construção inteira, não só pelo verbo. O Observador/locutor compartilha o conhecimento sobre a Entidade Focalizada com o interlocutor. Assim, para a Semântica de Frame, o conhecimento de mundo é

\footnotetext{
${ }^{2}$ A Gramática Normativa insiste em prescreve que verbo Existir, no sentido existencial, deve concordar com o objeto direto, porém, conforme Castilho (2014), a concordância verbal é controlado pelo Sujeito da oração, sendo que nas sentenças existenciais o Sujeito é inexistente. Por isso, manteve-se o exemplo (14) na forma como foi verificado, sem a concordância.
} 
imprescindível para a interpretação de enunciados e isso é um requisito exigido pelas sentenças existenciais.

Para Ferrari (2014), o frame é o que permite explicar por que a interpretação de um enunciado envolve sempre mais informações do que aquelas diretamente codificadas na forma linguística. Assim, as sentenças existenciais (14), (15) e (16) já abrigam o conhecimento compartilhado acionado pelos itens lexicais instanciados em cada sentença. Por exemplo, em (14), "Existe livros na biblioteca" o locutor e o interlocutor compartilham o conceito de livros e, também, de biblioteca, ao mesmo tempo há o compartilhamento de toda uma rede de ações que se realiza na biblioteca e comportamentos próprios nessa instituição.

Segundo Lyons (1977), o pilar básico para a condição de existência é o aspecto locativo ou temporal. Para esse autor, a existência está pautada no espaço e tempo. Givón (2012) também afirma que o 'existir' só seja possível 'no espaço' e 'no tempo'. Por consequente, as sentenças existenciais, na maioria dos casos, têm no seu design a marcação locativa-temporal. Como nos exemplos a seguir:

(17) Há dias nessa estrada. (comentário)

(18) No estoque da loja há produtos seminovos! (propaganda)

(19) Tem tanta coisa para resolver nesse país. (manchete)

Nota-se que as sentenças existenciais apresentam em comum um marcador locativo ou temporal no cerne do seu design gramatical. Vários autores afirmam que esse aspecto é uma marca que caracteriza essas sentenças (PEZZATI, 1993; CASTILHO, 2014). Todavia, em várias ocorrências, não aparece esse marcador locativo temporal. Nesses casos, aciona-se a Escala Implicacional de Givón (2012) para compreender a ausência dessa codificação. A saber: Existir no tempo> Existir no espaço > Existir.

As sentenças existenciais que dispensam o marcador locativo-temporal se localizam no polo mais abstrato dessa Escala Implicacional. Dessa forma, a Entidade Focalizada apresenta um grau de maior compartilhamento de conhecimento entre os interlocutores que não cabe marcar o Campo Visual da cena conceptual por ela ser identificada.

A Semântica de frame aponta para a descrição da cena conceptual que dá base ao enunciado, afinal é dela que decorre a intepretação das expressões linguísticas instanciadas no enunciado. Para Pinheiro (2010), o conceito de existência e posse correspondem a graus diferentes de abstração. $O$ autor utiliza o construto teórico conhecido como esquema imagético, pois representa de forma abstrata ou esquemática padrões experienciais básicos, resultado das interações sensórios-motoras diretas do ser humano com o seu meio ambiente.

Pinheiro (2010) demonstra que tanto o conceito de existência e posse estão submetidos a mesma experiência sensória-motora, porém, com base na noção de esquema imagético, chega-se as premissas: ter alguma coisa é ser um espaço que contém essa coisa; existir é estar contido em um espaço. Dessas premissas, podemos observar que o conceito de existência é constituído pela noção de espacialidade, por consequente, as sentenças existenciais instanciam um marcador locativo-temporal na maioria das ocorrências. Exemplos:

(20) Há um jeito de se dá bem na vida! (manchete) 
(21) Tem uma mulher na beira da praia. (comentário)

(22) Existe uma saída nesse prédio. (propaganda)

Observa-se que as expressões locativas de (20), (21) e (22) reproduzem o contorno locativo. Com isso, essas sentenças fazem referência a esse esquema que representa a experiência do Observador no meio ambiente. Assim, em paralelo, Fillmore (1982) afirma que a presença de diversos conhecimentos é responsável para a construção de um significado. Sendo esses conhecimentos estruturados em forma de frame que permitem aos falantes de uma língua se entenderem e usarem as palavras.

A partir da perspectiva da Linguística Cognitiva, e principalmente da Semântica de Frames, afirma-se que a sentença existencial é um construto conceptual. E, também, é independente do verbo utilizado nas sentenças que instanciam esse construto. Isso se afasta da perspectiva normativa e justifica as pesquisas sociolinguísticas, pois defendem que a seleção do verbo, de certa forma, não interfere no significado como todo, nesse caso existencial.

Ressalta-se que o sentido de um item lexical ou um padrão sintático pode ser submetido a uma descrição que considere os aspectos mais concretos da experiência humana mediada pela cognição. $\mathrm{E}$ esse sentido é constituído numa teia de sentidos baseados em experiências socioculturais do grupo de usuários da língua, isso pressiona o sistema linguístico.

\section{Palavras Finais}

Este trabalho verifica a constituição do sentido existencial a partir dos procedimentos da Semântica de Frames. Nessa perspectiva, o sentido resulta de um conjunto de conhecimentos de mundo estruturados na cognição e explanados nas expressões linguísticas, desde sua construção até sua intepretação. Com ponto de partida, consideramos as sentenças denominadas existenciais que ocorrem com verbos Ter, Haver, Existir em um design gramatical específico como: (i) verbo preposto ao Sintagma Nominal, (ii) verbo em terceira pessoa do singular, ou seja, impessoal, no presente do indicativo, (iii) expressão locativa-temporal.

Percebemos que o sentido de existência instanciado por sentenças com esses verbos envolve outras noções como a de espacialidade-temporalidade, a de compartilhamento de conhecimento sobre a Entidade Focalizada, sendo essas noções básicas para sua intepretação. Assim, independente do verbo selecionado (Ter, Haver ou Existir), o sentido existencial é mantido. Dessa forma, a escolha depende da perspectiva do falante no ato de enunciação, além de condições sociais como escolaridade.

Assim, a proposta da Gramática Normativa, que visa prescrever a forma verbal correta para as sentenças existenciais, afasta-se das pesquisas Sociolinguísticas que demonstram com dados que a seleção de verbos para essas construções atende vários fatores, principalmente o nível de escolaridade do usuário da língua. Entretanto, problematizamos que o significado existencial na língua é perfilado no padrão morfossintático, baseado nas noções básicas de espacialidade e compartilhamento de conhecimento sobre o referente.

Contudo, alinhamos com o princípio básico da Linguística Cognitiva da não separação restrita entre léxico e sintaxe, assim como a aceitação da relação entre palavra e mundo mediada pela cognição. 
Por consequente, o significado deixa de ser um reflexo direto do mundo e passa a ser visto como uma construção cognitiva através da qual o mundo é apreendido e experienciado, visto que as palavras e as sentenças não contêm significados, mas orientam a construção do sentido.

\section{Referências}

ALMEIDA, N. Gramática Metódica da Língua Portuguesa. São Paulo: Saraiva, 1999.

AVELAR, J. De verbo funcional a verbo substantivo: uma hipótese para a supressão de haver no português brasileiro. Letras de Hoje, Porto Alegre, v. 41, n. 1, p. 49-74, $2006 a$.

BECHARA, E. Moderna Gramática Portuguesa. Rio de Janeiro: Lucerna, 2006.

CASTILHO, A. T. Nova Gramática do Português Brasileiro. São Paulo: Contexto, 2014.

COSTA, Lucas A. Construções existenciais no português brasileiro. 2018. 125f. Dissertação (Mestrado em Letras e Linguística) - Faculdade de Letras, Universidade Federal de Goiás. Goiânia, 2018.

CUNHA, C. \& CINTRA, L. Nova Gramática do Português Contemporâneo. Rio de Janeiro: Nova Fronteira, 2001.

CHOMSKY, Noam. Syntactic structures. The Hague, Netherlands: Mouton Publishers, 1957.

FERRARI, Lilian. Introdução à Linguística Cognitiva. Ed. Contexto. São Paulo: 2014.

FILLMORE, C. J. The case for case. In: Bach, E., Harms, R. T. (Eds.). Universals in linguistic theory. Holt, Rinehart and Winston, Inc., 1968, p.1-88. 1968.

Hánshin, 1982. Frame Semantics. In. Linguistic Society of Korea (Ed.). Linguistics in the Morning Call. Seoul: 254. Frames and the semantics of understanding. In Quaderni di Semantica, v. 6, 1985, p. 222 -

FILLMORE, C. J. \& ATKINS, B. T. S. Toward a frame-based lexicon: the semantics of RISK and its neighbors. In. LEHRER, A. \& KITTAY, E. F (eds.). Frames, Fields, and Contrasts: new essays in Semantic and Lexical organization. Lawrence Erlbaum Association, 1992, 75 - 102.

GAWRON, J. M. Frame Semantics. San Diego, CA: San Diego State University. Disponível em: <http://www.cs.rochester.edu/u/james/Papers/029-FrameSemantics-Gawronfinal.pdf>. Acesso em: 24 out 2018.

GIVÓN, Talmy. A Compreensão da gramática. Ed. Cortez e Ed. UFRN, 2012.

GUREVICH, O. I. Constructional Morphology. The Georgian Version. 257 f. Thesis (Ph.D), University Of California, Berkeley, 2006.

LYONS, J. Semântica I. Lisboa: Editorial Presença/Martins Fontes, 1977.

LEITE, Y.; CALLOU, D. Como falam os brasileiros. Rio de Janeiro: Jorge Zahar Editora, 2002.

PEZATTI. E.G. A ordem de palavras e o caráter nominativo/ergativo do português falado. ALFA: Revista de Linguística. v. 15 p. 13-25, 1993.

PETRUCK, M. R. L. Frame Semantics. In. Jef Verschuerem et. al (Eds.). Handbook of Pragmatics. Philadelphia: John Benjamins, 1996.

PINHEIRO, Diogo. O papel da metáfora na relação entre sentenças possessivas e existenciais. Anais do IX Encontro do CELSUL, Palhoça, SC. 2010.

OLIVEIRA, Carolina Sartori de. A variação entre ter e haver em construções existenciais na fala e na escrita da variação rio-pretense: uma análise dos grupos de fatores relevantes. São Paulo: Revista Estudos Linguísticos. v. 43 (1), p. 515-528, 2014.

SACCONI, L. Nossa gramática: teoria e prática. São Paulo: Saraiva, 2001.

SALOMÃO, M. M. M.. Tudo certo como dois e dois são cinco. In.: MIRANDA, N. S. \& SALOMÃO, M. M. M. Construções do Português do Brasil: da Gramática ao Discurso. Belo Horizonte: Editora UFMG, p. 33 - 74, 2009. TAMBA, Irène. A Semântica. Ed. Parábola. 2012.

TRASK, Larry. Línguas genderless Basca. Publicação eletrônica, Linguist List. 1995.

VITORIO, E. Ter/haver existenciais na escrita de alunos dos ensinos fundamental e médio da cidade de Maceió/AL. 2008. Dissertação (Mestrado em Letras e Lingüística) - Universidade Federal de Alagoas, Alagoas, 2008. 